\title{
Patterns of News Media Consumption among Young People in Libya
}

\author{
Mokhtar Elareshi ${ }^{1}$ and Barrie Gunter ${ }^{1}$ \\ (1 Department of Media and Communication, University of Leicester, UK)
}

\begin{abstract}
The purpose of the study was to investigate patterns of major local and non-local news suppliers operating across a range of mediabroadcast and print - and relationships between Libyan undergraduate students' consumption of different news media platforms. A survey was administered to a sample of 400 students at Al-Fateh University using a stratified random sampling approach with sampling strata set by demographic groups. The new TV news services played an important role in attracting young Libyans with information they desire. The spread of new news media sources ( $T V$, radio, and print) in Libya has created a new type of news product that transcends national boundaries. The findings indicated that there were distinct news consumption-related population sub-groups defined in part by news platform (TV vs. radio vs. print) and in part by type of news supplier (local vs. international TV news operations). These findings indicated the emergence of new niche markets in news in Libya.
\end{abstract}

Key words: news consumption; news interest; youth; Libyan media; Arab satellite TV.

\section{Introduction}

News markets around the world are becoming increasingly crowded and competitive as new suppliers come on stream and old suppliers expand their businesses via old and new technology distribution platforms. The rapid developments that have taken place with digital technologies have driven this market expansion. The emergence of the Internet has been one driving force, but so too has the growth of digital broadcasting. New news suppliers are posing important challenges to established news brands in terms of market share and this in turn has impacted upon the resources available to continue supplying high quality news.

Unprecedented expansion of news providers has occurred in the Arab world. This has not only introduced competition for audiences for local news services, it can also pose new challenges for governments in non-democratic societies where the media are largely government controlled. Such news expansion has been occurring in Libya. Here, this has been dominated by the appearance of new satellite broadcast TV news services uplinked from outside Libya. These services are better resourced than local TV news suppliers and provide glossier productions with more diverse international news coverage. Such attributes have rendered these services particularly attractive to younger news consumers.

The findings reported in this paper derive from new research that explored the news consumption habits of young, better educated Libyans. It examines data on the reported use of major local and non-local news suppliers operating across a range of media - print and broadcast. The principal aims of this investigation were to produce new, up-to-date data on news consumption patterns, to find out whether different news media catered to distinctive demographic markets and to explore the relationships that might exist between consumption of different news media. 


\section{Overview of Libyan News Media}

This paper looks into the relationships between university students' consumption of different news from old and newly established media in Libya. There has been a dramatic expansion of news provision in Libya in the last decade and this has been manifest on television, radio, newspapers and the Internet (IREX. 2006). As of 2006, more than nine Libyan satellite TV channels were established along with 18 national and local radio stations. In addition to the main six local print media two new newspapers were launched in $2007 .^{1}$

Libyan media, like those in most other Arab nations, is government controlled and tasked with promoting the achievements of the country. The government appoints news editors and managers to ensure the major media work like mouthpieces for the nation (Amin 2002). Recent developments, however, have begun to change this scenario and news new media operations, especially those available via satellite broadcast television, have exposed Libyans to points of views and perspectives on issues that may not always be consistent with the policy positions of the Libyan government.

These changes have been exhibited via news services available on television and radio, in newspapers and via the Internet. The latter has been seen as an important factor in developing local media and creating new online social networks embracing different users who are given greater freedom in such environments to discuss news issues more openly. These communications technology developments have changed news production practices and presentation formats. For example, all the local newspapers can now be read electronically.

The development of local media was initiated when Al Gadhafi's son Saif Al lslam announced the launch of new free non-governmental media services (IREX. 2006). These started with a new satellite television service called Allibiya (now called $A l$ Jamahiriya2) in 2006 and a new radio station called Allibya FM. These were the first private media broadcasting stations in the nation. He then established the Al-Ghad Group for Media Services to publish two newspapers - Oea based in Tripoli and Qurena based in Benghazi (IREX. 2006, Arab Press Network. 2007).

These newspapers were published online and have proved to be very popular with readers and facilitated production efficiencies and economies as compared to the publication of hard copy newspapers. These two news publications have established their own niche markets in Libya and have learned lessons from other e-newspaper initiatives that have proven effective in catering to readers' needs across the Arab world (AlShehri, Gunter 2002).

Readers of Qurena's website can find up-to-date news which is relevant to Libyan readers and offers a wider news agenda that more traditional Libyan news media including stories that would normally have been restricted by government regulation. Traditionally, journalists in Libya have not been allowed to published or broadcast critical accounts of government decisions or policies (Amin 2002). Instead, they have been expected to reinforce the political status quo. More importantly, Oea and Qurena have opened possibilities for online interactions to take place between readers and journalists working on these publications.

Just as satellite broadcasts have expanded the range of choices of televised news provided to Libyans, there has also be an expansion in numbers of radio stations. Since 2000, the number of Libyan radio stations has been gradually increased from four radio stations in 1980s to eleven in 2000 (Al-Asfar 2002, Elfotaysi 1996). In 2010, there are twenty two national and local radio stations. Four of them provide regular international and regime news broadcast - Al Jamahiriya Radio Broadcasting, 
Voice of Africa, the Voice of Friendship and Solidarity, and Radio local Tripoli-, while the rest of others concern to broadcast mainly local news, Arab and Western music, sports news, and other local social activities and are located in the major Libyan cities (Al-Asfar 2002). In this study, three radio stations - Allibiya FM, Tripoli FM and Voice of Africa - were examined to report the difference of use of radio news. These stations mainly provide different news on a typical day. The first two are new radio stations and their news cover the area of Tripoli, where the research took place. These stations are mostly be used by university students and young adults.

\section{Young People's Use of News Media}

The relationship between young adults and use of news media has been studied for many years (Sherr 2005). It has been observed that young people display a weak interest in conventional forms of news and have been less likely than older people to engage with traditional news sources (Sherr 2005, Kaufhold 2008). In general, young adults were found to rely primarily on TV as their main source of news (Walma van der Molen, J.H., van der Voort 2000a). Even with television, however, older viewers were more likely than young adult viewers to use television news. Nevertheless, interest in news was observed to increase across university years among students (O’Keefe, Spetnagel 1973).

News consumption has generally been regarded as important as a vital source of information for citizens living in political democracies who may be called upon to vote upon or in other ways express their opinions about government actions and policies. Research has found moderate associations between young people's news consumption and their political awareness (Chaffee, McLeod \& Wackman 1973, Conway, Stevens \& Smith 1975). Atkin and Gantz (1978) found that there was a positive correlation between news exposure and current affairs knowledge. Gunter, et al (2000) found that children learn the most from TV news that has visual-verbal message redundancy. The latter finding can apply to young adults as well (Walma van der Molen, J.H., van der Voort 2000a, Neuman, Just \& Crigler 1992).

Since late 1980s, research has revealed that people may learn more from print news media than from televised news. The effectiveness of televised news, however, regardless of how important people believe it to be, does depend critically on the use of different production techniques by television newsrooms (Gunter 1987, Robinson, Levy 1986b). Research with teenagers and young adults, however, has indicated that television news can impart as much of not more information than newspapers under conditions where greater care is taken on the use of television production techniques (2000a, Walma van der Molen, J.H., van der Voort 1997, 2000b).

Despite much evidence highlighting their lack of apparent interest in news, young people tend to display an emergent awareness of news issues and propensity to consume news as they enter adulthood. Henke (1985) found that media consumption and its perceived importance both increase across their years at university among undergraduate students. Jamal and Melkote (2008) discuss that individuals identified as active processors of news and aware receivers of content select different kinds of media programmes and apply techniques of exposure to obtain calculable satisfactions.

\section{News Consumption Habits in the Arab World}

News consumption habits in the Arab world have been the subject of a number of studies that sought to determine the influences that drive this behaviour and the 
relationships between news sources and public affairs media exposure (Miladi 2006, Rugh 2004, Ayish 2001, Karam 2007b, Fandy 2007, Zayani, Ayish 2006). Some researchers have also examined not just what pulls people towards the news but also the facts that may steer them away from it. Marghalani, Palmgreen and Boyd (1998) indicated among a Saudi Arabian sample that that 'religious beliefs' and opinions about 'western commercialisation' (p.297) of the news are among the factors keeping people away from some TV news services.

Libyans have free access to news sources in multiple formats on several technology platforms. This rapidly evolving news landscape opens up questions about how media consumers in this country make decisions concerning which source to turn to for their news information. How do popular new international news channels in Arabic such as Al Jazeera TV and Al Jamahiriya2 TV impact upon the use of longer established locally-produced news sources? Evidence spanning many decades has indicated that new media can displace old media when both cater to the same audience needs and gratifications but do so in a more attractive manner (Levy, Windahl 1984, Heikkinen, Reese 1986, Wright 1960). This raises questions about whether news consumption patterns in Libya have been shifting as a result of the emergence of new news services in the newsprint, radio and television sectors.

It has already been found that Libyan audiences have been pulled away from the long-established local TV services as a consequence of the introduction of satellite TV channels in the late 1990 s. Nearly nine out of ten $(87 \%)$ of satellite users reported they watched local channels less since the spread of the satellite channels (Al-Asfar 2002). Commonly, the most frequently watched satellite TV channels among Libyan audience are MBC, Al Jazeera, Egyptian Channel, Dubai, Lebanese Future, Abu Dhabi, and LBC (Al-Asfar 2002, Marghalani, Palmgreen \& Boyd 1998, Karam 2007a, Jamal 2009).

Although Arab media organizations are interested in increasing their young audience, whether providing coverage about serious political matters is the way to success is debatable. Some commentators have argued that news providers targeting younger audiences should focus on more entertainment news and fast-paced presentation formats (Sherr 2005).

\section{Why Young Adults?}

The research presented in this paper has focused on news consumption among young adults in Libya. Although not representative of the whole population of media consumers in this country, young adults are important as the audiences both of the present and of the future. During their late teens and early 20s, young people begin to establish a bigger appetite for news. It is during this period of their development also when they become more actively politically engaged and turn to news media in this context (Henke 1985, Karam 2007a, Vincent, Basil 1997). Young people nevertheless may display distinct preferences in the news topics that appeal to them and in the news sources they consume to use different news sources for news reason (Pew Research Centre for the People \& the Press 2002, Pew Internet \& American Life Project 2010).

In this paper, we explore whether Libyan university students prefer new or old news sources or use both together. It is possible, for instance, that new and old news services cater to distinct niche markets. The current analysis is underpinned by the following research questions:

$R Q 1$. Which news services (TV, radio, and newspapers) are the most popular news sources among students? 
$R Q 2$. What relationships exist between consumption of news services presented via different media?

$R Q 3$. Do new news media and old news media attract distinct audiences?

$R Q 4$. Are there any distinctive demographic market differences in the consumption of different news media?

\section{Methodology}

A survey was carried out in December 2009 with a sample of 400 university students at Al-Fateh University, which is the biggest university in Libya. A stratified random sampling approach was applied on the University's student population, with sampling strata set by age, gender, subject being studied, and family size and income. A self-completion questionnaire was administered in classroom settings with either the first author or an assistant as moderator.

The questionnaire obtained details about respondents' personal demographic attributes (as indicated in relation to sampling strata above), study details, and reported consumption of different news media in Libya. A range of other questions were asked about respondents' news interests, motives for using different news media and perceptions of the importance of different types of news. Data on the latter measures are not reported in this paper which focuses on the characteristics of consumers of print and broadcast media and relationships between the consumption of different news media.

Respondents were asked to state how often they used different news sources for news and how much they consumed different news media from a list of news platforms. The list contained (a) news on the main Libyan TV channels including $A l$ Jamahiriya, Al Jamahiriya2, terrestrial and Al Shbabiya (b) news on channels from Arabic countries consisting of Al Jazeera, Al Arabiya, ANN News and $M B C$ (c) news on channels broadcast from non-Arabic-channels comprising Al Hurra, BBC (Arabic), France24 (Arabic), Russia Today (Arabic), and Al Alam Today (Arabic) News (d) news in newspapers containing Al Jamahiriya, Al Shams, Al Fajr Al Jadeed, Al Shat Oea, and Quryna (e) news on local radio including Allibiya FM, Tripoli FM and Voice of Africa.

Reported frequency of use responses were recorded originally on a five-point scale from 'daily' (1) to 'never' (5). After initial frequency distributions were computed, this scale was collapsed to three-point scale (with scoring reversed), by combining 'daily' and '4-6 days per week' to become Daily (3) and combining '1-3 days per week' and 'less than once a week' to become Occasionally (2) while keeping the 'never' (1) point intact.

\section{Results}

Data are reported in turn for claimed use of different TV news services, radio news services and then newspapers in Libya. The demographic profiles of television news, radio news and newspaper consumers are presented followed by analyses exploring relationships between the reported consumption of news services within each medium. Finally, data are presented on relationships between reported use of all major news media in Libya, across all media, via bi-variate correlational analyses and factor analysis which explores how use of different news services clusters into different 'families' of suppliers. 


\section{Reported Use of Different Television News Channels}

Respondents were required to specify in more precise terms the sources to which they turn for their news. These include reported use of specific news programmes or news publications. At this level of measurement, the paper turns to the reported use by university students of named news 'brands'. It begins with general descriptive data on frequencies of reported use of different named news sources, followed by examination of independent variables differences in claimed use of these sources. These analyses are concerned principally with the question of whether greater reported use of the new satellite TV news broadcasts is associated with less frequent use of older news media in Libya.

\section{Most Watched Television Channels}

Respondents were asked to state their most watched news TV channel on a list of thirteen news TV channels was given. The most watched TV news channels were: the Middle East Broadcasting Centre (MBC) (67\%); Al Jazeera (59.5\%); Al Shbabiya (56.8\%); Al Arabiya (50.2\%); Al Jamahiriya2 (41\%); Al Jamahiriya (34\%); Al Jamahiriya (Terrestrial TV) ${ }^{2}$ (29.3\%); Al Hurra (16.5\%); BBC (Arabic) (14.8\%); Al Alam Today (Arabic) (13\%); ANN News (9.8\%); France24 (Arabic) (7.5\%); and Russia Today (Arabic) (4.2\%).

There were significant gender differences in reporting use of specific TV channels. Such differences emerged for five TV channels: Al Jazeera, MBC, Al Hurra, BBC (Arabic) and Russia Today (Arabic) TV. Male students were more likely than female students to watch news via Al Jazeera (68.5 percent vs. 53 percent) (Mann-Whitney U test: $U(398)=16396.50$; exact $P<.01,2$-tailed), and slightly more likely to view $A l$ Hurra (17.3 percent vs. 15.9 percent) $(U(398)=17468.0$; exact $P<.05$, 2-tailed), and fairly more likely to watch news through BBC (Arabic) (18.5 percent vs. 12.1 percent) $(U(398)=16610.0$; exact $P<.01,2$-tailed $)$. However, females were more likely than males to watch news via MBC (74.1 percent vs. 57.1 percent) ( $U$ (398) $=16410.0$; exact $P<.01,2$-tailed) and slightly more likely to watch Russia Today (Arabic) (4.3 percent vs. 4.2 percent) $(U(397)=17381.0$; exact $P<.05$, 2-tailed).

There were a number of significant age ${ }^{3}$ differences in watching news television services. The differences emerged for two news channels: Al Shbabiya TV and $A l$ Jazeera. Al Shbabiya is a new Libyan TV channel was established in 2008 and its target is to satisfy young Libyan viewers. Those aged 17 to 20 years $(M=2.51)$ exhibited the highest consumption of news via Al Shbabiya TV, more than those aged 21 to 24 years $(\mathrm{M}=2.45)$ and 25 and above $(\mathrm{M}=2.16)$ (Kruskal-Wallis $\mathrm{H}$ test: $X^{2}$ $(2, N=400)=7.48, P<.05)$. The 25 year olds and above $(\mathrm{M}=2.72)$ indicated more consumption of news via Al Jazeera TV compared with those aged 17-20s $(\mathrm{M}=2.34)$ and those aged 21-24 $(\mathrm{M}=2.56)\left(X^{2}(2, N=400)=13.79, P<.01\right)$. Auter et al (2005) found that young people engaged with Al Jazeera at a higher parasocial level than did older adults. This meant that Al Shbabiya TV was able to draw teenage students' attentions to their news programmes which were usually light programmes, while $\mathrm{Al}$ Jazeera TV did so with mature students who might seek news and information.

There were significant Faculty-related differences in watching news programmes on the six named TV news channels: Al Jamahiriya, Al Jamahiriya2, Al Jamahiriya (Terrestrial TV), Al Shbabiya, MBC and Al Alam Today (Arabic) TV. While SSAL ${ }^{4}$ respondents were more likely to watch new on Al Jamahiriya (Terrestrial TV), Al Shbabiya TV and MBC TV than did AVM and NST respondents, AVM students consumed more news via Al Jamahiriya TV, an old local channel, Al Jamahiriya2 
TV, a new local channel established in 2007, and the Iranian TV Al Alam, a news channel based in Tehran. The Kruskal-Wallis $\mathrm{H}$ value for Terrestrial TV was $X^{2}$ $(2, N=400)=13.70, P<.01$, for Al Shbabiya was $X^{2}(2, N=400)=28.51, P<.001$, for MBC TV was $X^{2}(2, N=400)=6.84, P<.05$, for Al Jamahiriya was $X^{2}(2, N=400)=8.04$, $P<.05$, for Al Jamahiriya 2 was $X^{2}(2, N=400)=15.34, P<.001$ and for Al Alam Today (Arabic) TV was $X^{2}(2, N=397)=8.93, P<.05$.

An additional analysis found that there were only two significant Family Size differences in watching news TV channels - Al Jamahiriya (Terrestrial) and BBC (Arabic) TV. Those who lived in family households of less than four people $(\mathrm{M}=2.14)$ were more likely to consume news via Terrestrial TV compared to those lived with large families of more than eight people $(\mathrm{M}=2.04)$, those lived by themselves $(\mathrm{M}=2.00)$ and those lived with medium-sized families of from four to eight people $(\mathrm{M}=1.82)\left(X^{2}(3, N=400)=9.30, P<.05\right)$. Further, those lived with small-sized families reportedly watched more news on BBC (Arabic) than did all the other family size groups $\left(X^{2}(3, N=400)=7.81, P<.05\right)$. Arguably, Terrestrial TV is more likely to maintain traditional cultural value programmes than are satellite TV channels. In the era of digital, however, new satellite Libyan television channels more than Terrestrial TV and older satellite Libyan channel appeared to have significantly and adversely affected on students' lives. This meant that the majority of students relied upon these channels to get news and information.

One surprise came from reported use of TV channels that none significant differences were observed among demographic groups and watching news on $\mathrm{Al}$ Arabiya TV, non-stop news established in 2003 and is based in Dubai. Respondents had similar responses and attitudes to this channel. It was assumed that Al Arabiya TV would compete with some international TV channels such as Al Jazeera TV.

\section{Relationships between Reported Use of Different Satellite TV News Services}

The correlational relationships between the reported news consumption habits here are based on the Spearman's rho test. The findings here are all that surprising signify that university students who consume news via one news TV channel are quite likely to consume news via other news channels. There were, however, strong correlation coefficients between reported consumption of local news TV channels. Thus, reported consumption of Al Jamahiriya TV was correlated significantly with reported consumption of Al Jamahiriya2 TV $\left(r_{s}=.52, P<.01\right)$, Terrestrial TV $\left(r_{s}=.43, P<.01\right)$ and $A l$ Shbabyia TV $\left(r_{s}=.37, P<.01\right)$. Those who were interested in watching local Libyan TV channels were more likely to watch news programmes via these TV channels.

Turning to international Arabic televised news services, there were also strong correlations between the reported consumption of news via these TV channels. The correlation analyses showed that watching news via Al Jazeera correlated with $A l$ Arabiya $\left(r_{s}=.60, P<.01\right)$ and $A N N$ News $\left(r_{s}=.23, p<.01\right)$. MBC TV associated with $A l$ Arabiya TV $\left(r_{s}=.22, P<.01\right)$. These results indicated that those who followed news via pan-Arab TV channels were more likely to watch news on these TV channels. These data also indicated that the new satellite pan-Arab TV news services were viewed mostly more widely than the local Libyan TV news services.

Further significant correlation coefficients emerged between reported consumption of different non-Arabic international TV news services. Thus, reporting viewing of BBC (Arabic) TV was associated with reported viewing of Al Hurra $\left(r_{s}=.46, P<.01\right)$, France 24 (Arabic) $\left(r_{s}=.42, P<.01\right)$, Russia Today $($ Arabic $)\left(r_{s}=.33, P<.01\right)$ and $A l$ 
Alam Today (Arabic) $\left(r_{s}=.31, P<.01\right)$. Also, reported viewing of Al Hurra was correlated with reported viewing of France24 (Arabic) $\left(r_{s}=.28, P<.01\right)$, Russia Today (Arabic) $\left(r_{s}=.21, P<.01\right)$ and Al Alam Today (Arabic) $\left(r_{s}=.33, P<.01\right)$. These results indicated that respondents who claimed to watch one non-local TV news service were also more likely to claim to watch other news services within this cluster.

For each of these correlational data, a factor analysis was run to determine the interrelationships among claimed use of different news channels. Each of these news channels were clustered into mostly consumed in terms of viewing frequency. The factoring criteria were: (a) minimum primary loadin $\S=.40$ on a facto $\mathrm{r}$; (b) a factor Eigenvalue $\leq=1$; and (c) each item has a loading $\leq=.40$. The principal components analysis, with the varimax rotation, yielded the most conceptually meaningful and factorally pure solution. Four factors with their Eigenvalues greater than one emerged, explaining $61.12 \%$ of the variation.

In order to investigate which news channels factors has the strongest endorsements by the respondents, the average mean scores were computed for the factor and ranked them. As mentioned earlier, the scale has collapsed into a three-point scale (with scoring reversed). The averaged mean ranking revealed that the most watched TV channels were Arabic entertainment TV channels, followed by Arabic TV channels, local TV channels, and non-Arabic TV channels. Table. 1 lists the news TV channels for each of the four factors with the corresponding factor loadings.

Table. 1 Factor Loading for Consuming News on Different News TV Channels

\begin{tabular}{|c|c|c|c|c|c|}
\hline \multirow{2}{*}{ TV channels } & \multicolumn{5}{|c|}{ Factors } \\
\hline & M & 1 & 2 & 3 & 4 \\
\hline Factor 1: Non-Arabic TV channels & 1.44 & & & & \\
\hline - France24 (Arabic) TV & 1.28 & .758 & & & \\
\hline - ANN News TV & 1.44 & .718 & & & \\
\hline - BBC (Arabic) TV & 1.60 & .694 & & & \\
\hline - Russia Today (Arabic) TV & 1.23 & .658 & & & \\
\hline - Al Hurra TV & 1.64 & .559 & & & \\
\hline - Al Alam Today (Arabic) TV & 1.49 & .538 & & & \\
\hline Factor 2: Local TV channels & 2.21 & & & & \\
\hline - Al Jamahiriya2 TV & 2.27 & & .790 & & \\
\hline - Al Jamahiriya TV & 2.20 & & .781 & & \\
\hline - Terrestrial TV & 1.92 & & .704 & & \\
\hline - Al Shbabiya TV & 2.45 & & .697 & & \\
\hline Factor 3: Arabic news TV channels & 2.41 & & & & \\
\hline - Al Jazeera TV & 2.47 & & & .860 & \\
\hline - Al Arabiya TV & 2.35 & & & .836 & \\
\hline Factor 4: Arabic entertainment TV channel & 2.56 & & & & \\
\hline - MBC TV & 2.56 & & & & .906 \\
\hline Eigenvalue & & 3.39 & 1.96 & 1.54 & 1.06 \\
\hline$\%$ variance explained & & 26.08 & 15.04 & 11.82 & 8.18 \\
\hline Cronbach's Alpha (reliability score \%) & & .76 & .74 & .74 & \\
\hline
\end{tabular}

Notes: Extraction Method: Principle Component Analysis. Rotation Method: Varimax (eigenvalue $>$ 1). News items measures on 3 -point scale $(1=$ never and $3=$ daily).

Internal reliability of factors was tested by Cronbach's alpha (.75), the Bartlett's test of sphericity was $1240.75(P<.01)$, and the KMO value was $.75, P<.01$. The factor 
analysis produced a very precise solution. Respondents could easily be clustered into those that were mostly non-Arabic TV channels consumers, those who were local Libyan TV channels consumers, those who were mostly Arabic news TV channels consumers and those who were Arabic entertainment TV channel consumers. The interrelationships between the different non-Arabic TV channels - even ANN News TV was an Arabic TV based on Syria, but it had a very strong correlations with nonArabic TV channels - were strong as can be seen its high Eigenvalue score. Internal consistency for this scale was the high (Cronbach alpha =.76). Further, the interrelationships among local TV channels and Arabic news TV channels were quite strong as shown by their Eigenvalue scores, with the same reliability scale scores (Cronbach alpha =.74). Surprisingly, the entertainment channel MBC TV was strongly loaded on a separate factor. While it was expected that MBC TV might load on Factor 3 with Arabic news TV channels, in the minds of respondents these TV channels apparently were closely connected. In fact, current events and news affairs used to be provided by MBC before Al Jazeera TV and Al Arabiya TV were launched (Ghareeb 2000).

\section{Reported Use of Specific Radio Stations}

Although the research focuses on satellite TV channels, it sits within the wider context of other media including radio, and newspapers. Here, one issue being addressed by this paper is whether the introduction of new radio stations that operate across Libya has drawn news consumers away from the longer established radio broadcast. In an initial attempt to explore whether this phenomenon is occurring, survey data on reported frequency use of different radio stations were examined using correlation analyses to find out whether greater reported use of one radio channel was associated with lesser or greater reported use of another radio.

It was found that the radio finished in second place and ahead of local TV services and newspapers. The majority (65\%) of respondents indicated that they obtained news via Allibiya FM - a new radio station - on a typical day. listening to Tripoli $F M$ - a new radio station - was the second source for the news $(33.5 \%)$. Unsurprisingly, the majority (66.7\%) of respondents claimed never access news via the Voice of Africaa longer established radio.

There were significant gender differences in reported listening to local Libyan radio. Females were more likely than males to listen to Allibiya $F M$ for news ( 87 percent vs. 82 percent) $(U(398)=17578.0$, exact $P<.05,2$-tailed $)$, and less likely to listen to Voice of Africa (45.6 percent vs. 50.6 percent) $(U(398)=17008.50$, exact $P<.01,2$ tailed).

There was a significant Faculty-related difference in reported listening to local radio for news, with those who AVM students $(\mathrm{M}=2.05, \mathrm{SD}=.79)$ and SSAL students $(\mathrm{M}=2.05, \mathrm{SD}=.83)$ being more likely than NST students to get new via Tripoli $F M\left(X^{2}\right.$ $(2, N=400)=8.520, P<.05)$, and also more likely to listen to Voice of Africa, $X^{2}$ $(2, N=400)=6.650, P<.05$.

There was only one significant Family Size and Family Income difference in respect of reported listening to Voice of Africa. Those who lived by themselves $(\mathrm{M}=1.71)$ and in low-income families $(\mathrm{M}=1.47)$ were more likely to say they listened to news via Voice of Africa than those lived in large family households of more than eight people $(\mathrm{M}=1.51)$ and those lived in families earning more than $£ 1000$ per month $(\mathrm{M}=1.36)$.

The correlations (Spearman's rho tests) among the three named radio stations revealed relatively moderate associations between Allibiya FM and Tripoli FM 
$\left(r_{s}=.38\right)$, Allibiya FM and Voice of Africa $\left(r_{s}=.17\right)$, and Voice of Africa and Tripoli FM $\left(r_{s}=.46 ; N=400\right.$, all $P_{s}<.01$, all 2-tailed). These correlations indicated weak degrees of association between listening to these different radio news services.

\section{Reported Use of Specific Newspapers}

Use of the press was generally reported at a lower level than use of broadcast news. When asked how often they read local newspapers, the majority of respondents indicated that they did not read local print media. However, the older-established newspapers such as Al Jamahiriya (24.7\%) and Al Shams (24\%) were more likely to be read than the new print. Less than one fifth of respondents indicated they read Oea, Quryna, and Al Shat newspapers. The reason behind low levels of reading local newspapers could be because respondents preferred to receive news by watching TV news rather than reading newspapers which are even not available for the readers all the time (Pew Research Centre for the People \& the Press 2002).

There were significant differences by Faculty-related in reported reading of local newspapers. SSAL respondents read more often news on Al Jamahiriya, Al Shams, Al Fajr Al Jadeed, and Al Shat newspapers than did both AVM and SNT respondents. Whereas, AVM respondents consumed more news on these newspapers than did SNT respondents. The Kruskal-Wallis $\mathrm{H}$ test for reporting use of Al Jamahiriya was $X^{2}$ $(2, N=400)=9.40, P<.01$, for Al Shams was $X^{2}(2, N=400)=11.33, P<.01$, for Al Fajr Al Jadeed was $X^{2}(2, N=400)=11.50, P<.01$, and for Al Shat was $X^{2}(2, N=400)=10.30$, $P<.01$. The results indicated students for the SSAL faculties tended to read more newspapers than those from AVM and SNT respondents. The significant results may be due to the nature of the SSAL students who were required to read more materials than any other students from any field of study. Thus, their exposure to reading environment is expected to be higher. This finding is consistent with Mokhtari and Sheorey (1994) who found that humanities students were found to read more than natural science, engineering, and math students.

There were a number of significant Year of Study differences regarding the reported frequencies of use of different newspapers. These differences appeared for three newspapers: Oea, Quryna and Al Shat. First-year students were more likely than fourth-year students to read news in Oea newspaper $(\mathrm{M}=1.84$ vs. $\mathrm{M}=1.61)\left(X^{2}\right.$ $(3, N=400)=8.933, P<.05)$, and more likely to read Quryna $\left((\mathrm{M}=1.74\right.$ vs. $\mathrm{M}=1.49)\left(X^{2}\right.$ $(3, N=400)=10.434, P<.05)$, and more likely to read Al Shat $(\mathrm{M}=1.62$ vs. $\mathrm{M}=1.43)$ $\left(X^{2}(3, N=400)=8.946, P<.05\right)$.

There was a significant Family Size difference in reading one newspaper, with those lived by themselves $(\mathrm{M}=2.57)$ read Al Shams more frequently than those lived with small family members of less than four people $(\mathrm{M}=1.77)$ and large families of more than eight people $(\mathrm{M}=1.88)\left(X^{2}(3, N=400)=7.692, P<.05\right)$.

There was a significant family income difference in reported use of Al Shat newspaper, with those lived by themselves $(\mathrm{M}=2.57)$ being more likely than those lived with middle family members of from four to eight people $(\mathrm{M}=1.48)$ and those lived with large families of more than eight people $(\mathrm{M}=1.88)$ to read news in this paper, $X^{2}(3, N=400)=15.382, P<.01$. There were no significant gender differences in reported read of news on any newspaper.

\section{Relationships between Reported Use of Different Newspapers}

A series of Spearman's rho correlations were computed between reported consumption scores of the six local newspapers. The results are summarised in Table 
2 the findings revealed significant correlations between most of these newspapers. Hence the more respondents claimed to read one local newspaper, the more they also claimed to read others.

Table. 2 Correlations (Spearman's rho) between the Reported Readerships of Different Newspapers

$\begin{array}{lccccc} & \mathbf{1} & \mathbf{2} & \mathbf{3} & \mathbf{4} & \mathbf{5} \\ \text { 1- Al Jamahiriya } & 1.00 & & & & \\ \text { 2- Al Shams } & .74^{*} & 1.00 & & & \\ \text { 3- Al Fajr Al Jadeed } & .63^{*} & .80^{*} & 1.00 & & \\ \text { 4- Oea } & .50^{*} & .58^{*} & .65^{*} & 1.00 & \\ \text { 5- Quryna } & .44^{*} & .46^{*} & .49^{*} & .69^{*} & 1.00 \\ \text { 6- Al Shat } & .41^{*} & .46^{*} & .46^{*} & .56^{*} & .58^{*}\end{array}$

\section{Factor Analytic Results of Reported Use of All Named News Sources}

A factor analysis was run to determine the interrelationships among reported use of all named news media. Criteria for factoring were the same as those adopted with data on reported use of TV news channels. Again, principal components analysis with varimax rotation yielded the most conceptually meaningful and factorally pure solution. Six factors with Eigenvalues greater than one emerged. Table 3 lists the news sources for each of the six factors with the corresponding factor loadings.

First the reliability of news media was tested by using a common reliability test of Cronbach's coefficient alpha (0.86). The Bartlett's test of sphericity was 3309.42 $(P<.000)$ and the KMO value was $.84, P<.000$. The result showed six factors with Eigenvalues greater than one that explained $62.70 \%$ of the total variance. All news sources had high reliability scores which indicated that news consumers could be clustered into six different news consumption groups. The interrelationships between both the different local newspapers and non-Arabic TV channels were particularly strong as evidenced by their higher Eigenvalue scores. However, the interrelationships among the other four factors were not as strong as revealed by their lower Eigenvalue scores. As it stated before the factor analysis here presents a very clear-cut solution that revealed even among university students that there were distinct news consumer segments in the population as defined by their preferred news sources.

Table 3 Factor Analysis Results of Reported Use of Named News Sources

\begin{tabular}{|c|c|c|c|c|c|c|}
\hline & \multicolumn{6}{|c|}{ Factors } \\
\hline & 1 & 2 & 3 & 4 & 5 & 6 \\
\hline \multicolumn{7}{|l|}{ Factor 1: Local newspapers } \\
\hline - Al Shams & .847 & & & & & \\
\hline - Al Fajr Al Jadeed Newspaper & .823 & & & & & \\
\hline - Oea Newspaper & .807 & & & & & \\
\hline - Al Jamahiriya Newspaper & .734 & & & & & \\
\hline - Quryna Newspaper & .728 & & & & & \\
\hline - Al Shat Newspaper & .633 & & & & & \\
\hline \multicolumn{7}{|l|}{ Factor 2: Non-Arabic TV channels } \\
\hline - France24 (Arabic) TV & & .746 & & & & \\
\hline - BBC (Arabic) TV & & .703 & & & & \\
\hline - ANN News TV & & 679 & & & & \\
\hline - Russia Today (Arabic) TV & & .663 & & & & \\
\hline
\end{tabular}


- Al Hurra TV

- Al Alam Today (Arabic) TV

Factor 3: Local TV channels

- Al Jamahiriya2 TV

.784

.746

.666

.655

- Al Jamahiriya (Terrestrial) TV

Factor 4: Arabic news TV channels

- Al Jazeera TV

- Al Arabiya TV

.857

.816

Factor 5: Local radio stations

- Tripoli FM

- Voice of Africa

.764

.710

- Allibiya FM

.541

Factor 6: Arabic entertainment TV channel

- MBC TV

Eigenvalues

$\begin{array}{llllll}6.04 & 2.31 & 1.81 & 1.43 & 1.14 & 1.06\end{array}$

$\%$ variance explained

$\begin{array}{llllll}27.46 & 10.50 & 8.25 & 6.50 & 5.18 & 4.83\end{array}$

Cronbach's Alpha (reliability score \%)

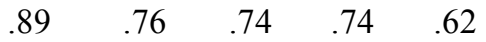

Notes: Extraction Method: Principle Component Analysis. Rotation Method: Varimax (eigenvalue >

1). News items measured on 3-point scale ( $1=$ do not use and $3=$ daily).

These findings indicated that there were distinct news consumption differences defined in part by news platform (television vs. radio vs. newspapers) and in part by type of news supplier (local vs. international TV news operations). This finding indicates that there might be new niche markets. There was support evidence that respondents consumed different news information from different news platforms.

\section{Discussion}

Research has been reported that examined the news consumption habits of young adults in higher education in Libya. This investigation came at a time when the news media landscape in Libya has undergone considerable change with the introduction of news television and radio news services and news services published via the Internet. Despite the scramble to establish new news services across the Arab world and in Libya in particular, little research has so far been undertaken to investigate the impact of these developments on patterns of news consumption (Karam 2007b, Sakr 2007b, Alzwai 2003, Al-Shaqsi 2000, Boyd, Shatzer 1993). The current study was designed in part to fill this gap. Certain questions were asked about the patterns of news sources consumption habits among young people, better educated, in Libya. It reported use of major local and non-local news suppliers (TV, print, and broadcast) to examine whether different news media provided to distinctive demographic markets and to explore the relationships between different news media.

This survey found that most respondents followed news on different platforms on a daily basis. In response to being asked to name their most preferred televised news service those mentioned most included MBC, Al Jazeera, Al Shbabiya and Al Arabiya. The demographic profiles of audiences for these new televised news services, however, were not invariably the same. Al Jazeera was found to be consumed by more often male students, aged 25+, and final-year students at university, while MBC and Al Shbabiya were preferred by females, aged 17-21, who were first-year university students.

These findings were confirmed by those of Johnson and Fahmy (2005), who found that males were more likely to be heavy consumers of Al Jazeera, while females were found to avoid watching this channel (Al-Asfar 2002, Jamal, Melkote 2008). MBC 
was originally designed to target female audiences, especially the young who like to watch fashionable woman programmes. The channel is a window in which delivers on what is produced by the Western culture and modified in Arabic style (Ghareeb 2000) such as programme Kalam Nawa'em (Sweet Talk) or Super Star.

Interestingly, Russia Today (Arabic) TV was found to be reportedly watched more by females than males. One source has claimed that the number of viewers watching its programmes is growing as more than 350 million Arab viewers around the world can watch it including news programmes, sports, films and documentaries (RT. 2010). Surprisingly, there were no significant differences observed among demographic groups in respect of claimed viewing of Al Arabiya TV.

When examining the links between reported consumption of news from different television news services, respondents displayed a degree of segmentation in terms of specific categories of news provider. Hence, there were respondents who watched local Libyan TV news channels, those who viewed international Arabic channels, and those who watched international non-Arabic channels. Thus, although some respondents displayed diverse news consumption tastes and sampled news from any different televised news services, it was clear that a propensity to watch a channel of one type was significantly correlated with a propensity to watch televised services from that same category.

Turning to radio news consumption, the descriptive statistics revealed three out of five of respondents said they listened to the two new local radio - Allibiya FM and Tripoli FM, and fewer consumed news via the Voice of Africa radio. The latter is an ideological station which aims to broadcast revolutionary guidance programmes and incite African people to struggle against Western culture. Because of this agenda this station has not proved to be appealing to young Libyan listeners. These findings largely confirm those of Bel-Hajj (2008). These radio stations revealed some overlap between their listeners, but this was not a strong feature of their respective audiences.

With regard to specific local newspapers, it was found that younger students were less likely than older students to read local newspapers, despite the new developments in local print news coverage. In general, newspaper readership was not as widespread among these respondents as was use of television as a news source. This finding is consistent with other research (Schlagheck 1998, Bogart 1989, Thurlow, Milo 1993). In contrast, a study by Abdul Karim and Hasan (2007) investigated students' reading habits and found that about three in four claimed to read newspapers everyday or at least a few times a week. Blackwood (1991) found that many final-year university students read newspapers and spent more time reading during vacations than when classes were in session.

Perhaps the most clear cut evidence of market segmentation of news audiences by type of news supplier emerged from the final factor analysis that combined reported use of all types of news supplier. Here, it was found that news consumption was defined by type of supplier. Hence, there were news consumers characterised respectively by consumption of local TV news or of international Arabic TV channels, or of international non-Arabic channels, or of radio stations, or of local newspapers. These findings are important because although there is evidence in Libya that newer news services might take news consumers away from older established news services, there may also be scope for the old and new to forge their own distinctive identities and attract their own distinctive audiences. 


\section{Conclusion}

This paper has given an account of the use of different news media. It has examined the news consumption habits of young adults in higher education in Libya, with special attention paid to their use of different news services (TV, radio and print). It reported the change of the news media landscape in Libya. It showed that the spread of new news media sources in Libya has established a new sort of customer that goes beyond national boundaries. The new televised news services have been able to capture the attention and interest of young Libyan news consumers. This raises an important question about the spread of new media sources, that is whether these new news services have pulled customers away from the old, established local news services.

The paper found that although most respondents obtain news from different news sources on a daily basis, what is clear from this study is that news consumers (respondents) of these news services show a great response to new media sources, such as Al Jazeera, and they have somewhat abandoned local media in favour of nonlocal services (Elareshi, Gunter 2010). This evidence suggests that local news media, new and old, should consider the technical and style they produce news programmes so they could gratify and satisfy the desires of young people in the future.

Perhaps the most clear-cut evidence of market segmentation of news audiences by type of news supplier emerged from the final factor analysis that combined reported use of all types of news supplier. The results of this study indicate that news consumption is defined by type of supplier. Hence, there are news consumers characterised respectively by consumption of local TV news or of international Arabic TV channels, of international non-Arabic channels, radio stations, or of local newspapers. These findings are important because although there is evidence in Libya that newer news services might take news consumers away from older established news services, there may also be scope for the old and new to forge their own distinctive identities and attract their own distinctive audiences.

This study represents the university students from the Libyan capital city, Tripoli. Therefore, the generalisability of this paper is limited to the students who were sampled from the university, and the findings are limited to the University of Al-Fateh itself. However, 400 participants may have provided a reasonable cross section. The current study is limited by the inherent limitation of self-reported measures and the sample size. An issue is that the development of news in Libyan media is not easily understood and reorganised by the audience, especially young adults who do not often read newspapers and watch TV. Also, the changes need more time to be observed and evaluated; for example, it took many years until Al Jazeera TV was reorganised as an important TV news channel.

Given the limitations of this paper, future research could investigate different demographics' perceptions of news media. This should include different classes from young adults to adults. Also, it would be worthwhile to study the effects of international media, such as Al Jazeera TV, on local media. As various local media tend to use new media, it would be meaningful to explore the effects of new media on traditional ones. Thus it seems interesting to consider the difference between new satellite TV channels and old ones in terms of programmes.

[7675words] 


\begin{abstract}
Note:
${ }^{1}$ The main Libyan satellite TV channels are Al Manawa (The Diversity), Al Jamahiriya, Al Nadi (The Club), Al Jamahiriya2 (the former Allibiya TV), Al Shbabiya (The Youth), Al Badeel (Alternative), Al Hedaya (Guidance), Al Jamahiriya Sport 1, and Al Mutawassit (Mediation). The main daily newspapers are Al Shams, Al Fajr Al Jadeed (in Arabic \& English versions), Al Zahf Al Akhder, Al Jamahiriya, and Akhbar Libya.

${ }^{2}$ In fact, there are many terrestrial channels can be received by antenna in Libya. In this study, however, the terrestrial TV refers to the local Al Jamahiriya TV which shares the same news and some programmes with A Jamahiriya Satellite Channel. Libyans watch Italian and Multan terrestrial TVs for entertainment reason even they do not spoken their languages

${ }^{3}$ For the purpose of this study age variable was divided into three sub groups: those aged 17-20 called teens, $21-24$ called young and $25 \&$ above called matures. The reason for this was to find whether there were significant differences among the same group.

${ }^{4}$ Faculty variable was clustered into three common faculties: [1] Faculties of Social Sciences, Arts and Law (SSAL) included Faculties of Arts \& Media, Arts; Education (Tripoli); Education (Janzour); Education (Ben Ghasheer); Languages; Physical Education; Economics \& Political Sciences; and Law. [2] Faculties of Natural Sciences \& Technologies (NST) included Faculties of Sciences; Engineering; and Information Technology. [3] Faculties of Agriculture and Veterinary \& Medicine (AVM) included Faculties of Agriculture and Veterinary \& Medicine.
\end{abstract}

\title{
Contributor details
}

Barrie Gunter is Professor of Mass Communications and Head of the Department of Media and Communication, University of Leicester. He has published 50 books and over 300 journal papers, book chapters and technical reports on a range of media, marketing and management topics. His recent books include: The Google Generation (with Ian Rowlands and David Nicholas, 2009, Chandos) and Television versus the Internet (2010, Chandos).

Mokhtar Elareshi is a lecturer at the University of Al-Fateh and the former Head Department of Media at Nasser Nation's University 2003-06. Elareshi earned his M.A in 2001 from University of Garyounis, Libya. Currently, he is a PhD student, University of Leicester, UK. His research focuses on the role of satellite TV channels as news sources in the lives of young people in Libya. Their e-mail addresses are [me94@le.ac.uk] and [bg45@le.ac.uk]

\section{References}

Abdul Karim, N.S. \& Hasan, A. 2007, "Reading habits and attitude in the digital age: Analysis of gender and academic program differences in Malaysia", The Electronic Library, vol. 25, no. 3, pp. 285-298.

Al-Asfar, M. 2002, Direct satellite broadcasting its impact on the audiences for local television channels in Tripoli Libya, PhD, University of Manchester, UK.

Al-Shaqsi, O.S. 2000, The influence of satellite and terrestrial television viewing on young adults in Oman : uses, gratifications and cultivation, $\mathrm{PhD}$, University of Wales. Cardiff.

AlShehri, F. \& Gunter, B. 2002, "The market for electronic newspapers in the Arab world", Aslib Proceedings, vol. 54, no. 1, pp. 56-70.

Alzwai, A. 2003, The impact of satellite channels on shaping the trends of young people in Libyan community: A field study of a sample of young people in Benghazi, Libya, PhD, Department of Social Studies and Research Institute Arab Studies League of Arab States, Cairo, Egypt.

Amin, H. 2002, "Freedom as a value in Arab media: Perceptions and attitudes among journalists", Political Communication, vol. 19, no. 2, pp. 125-135.

Arab Press Network. 2007, 09/02/2011-last update, Can media owned by Gaddafi's son be free?. Available: http://www.arabpressnetwork.org/articlesv2.php?id=1469 [accessed on 2011, February 09].

Atkin, C.K. \& Gantz, W. 1978, "Television news and political socialization", Public Opinion Quarterly, vol. 42, no. 2, pp. 183-198. 
Auter, P., Arafa, M. \& Al-Jaber, K. 2005, "Identifying with Arabic journalists: How Al-Jazeera tapped parasocial interaction gratifications in the Arab world", International Communication Gazette, vol. 67, no. 2, pp. 189-204.

Ayish, M. 2001, "American-style journalism and Arab World television: An exploratory study of news selection at six Arab World satellite television channels", The Ethics of journalism: Comparison and Transformations in the Islamic-Western Context.

Bel-Hajj, S. 2008, "Patterns of public exposure to Allibiya FM", Al-Buhuth Al-Ealmiaa, , no. 43, pp. 67-120 [in Arabic].

Blackwood, C. 1991, "Pleasure Reading by College Students: Fact or Fiction?", the Mid-South Educational Research Association, pp. 13.

Bogart, L. 1989, Press and Public: Who Reads What, When, Where, and Why in American Newspapers, Lawrence Erlbaum Associates, Hillsdale, New Jersey.

Boyd, D.A. \& Shatzer, M. 1993, "Television viewing habits of Saudi Arabian young adults", Gazette, vol. 51, pp. 137-148.

Chaffee, S.H., McLeod, J.M. \& Wackman, D.B. 1973, "Family communication patterns and adolescent political participation" in Socialization to Politics, ed. D. Jack, A Reader, New York: Wiley, pp. 349-364.

Conway, M.M., Stevens, A.J. \& Smith, R.G. 1975, "The relation between media use and children's civic awareness", Journalism Quarterly, vol. 52, no. 3, pp. 531-538.

Elareshi, M. \& Gunter, B. 2010, "News consumption among young Libyan adults: Are new satellite TV news services displacing local TV news?", Arab Media \& Society, [Online], no. Winter, pp. 2010. Available from: http://www.arabmediasociety.com/?article=759. [accessed on 13 December 2010].

Elfotaysi, J. 1996, The development and structure of Libyan television broadcasting 1968-1995, PhD, University of Leeds, UK.

Fandy, M. 2007, (UN) Civil War of Words: Media and Politics in the Arab World, PRAEGER, London.

Ghareeb, E. 2000, "New media and the information revolution in the Arab world: An assessment", The Middle East Journal, vol. 54, no. 3, pp. 395-418.

Gunter, B. 1987, Poor reception: misunderstanding and forgetting broadcast news, Lawrence Erlbaum Associates, Hillsdale, New Jersey.

Gunter, B., Furnham, A. \& Griffiths, S. 2000, "Children's memory for news: A comparison of three presentation Media", Media Psychology, vol. 2, no. 2, pp. 93-118.

Heikkinen, K. \& Reese, S. 1986, "Newspaper readers and a new information medium", Communication Research, vol. 13, no. 1, pp. 19-36.

Henke, L. 1985, "Perceptions and use of news media by college students.", Journal of Broadcasting and Electronic Media, vol. 29, no. 4, pp. 431-436. 
IREX. 2006, , Media sustainability index 2005: The development of sustainable independent media in the Middle East and North Africa. Available: http://www.irex.org/programs/MSI_MENA/2006/MSIMENA06_Libya.asp [accessed on 24 March 2009].

Jamal, A. \& Melkote, S. 2008, "Viewing and avoidance of the Al-Jazeera satellite television channel in Kuwait: A uses and gratifications perspective", Asian Journal of Communication, vol. 18, no. 1 , pp. 1-15.

Jamal, A. 2009, "Media culture as counter-hegemonic strategy: the communicative action of the Arab minority in Israel", Media, Culture \& Society, vol. 31, no. 4, pp. 559-577.

Johnson, T.J. \& Fahmy, S.S. 2005, "The CNN of the Arab world or a shill for terrorists? How support for press freedom and political ideology predict credibility of al-Jazeera among its audience", The annual meeting of the International Communication Association.

Karam, I. 2007b, "Satellite Television: A Breathing Space for Arab Youth?" in Arab Media and Political Renewal: Community, Legitimacy and Public Life, ed. N. Sakr, I.B. Tauris \& Co Ltd, London, pp. 80-95.

Karam, I. 2007a, Arab satellite broadcasting, identity and Arab youth, $\mathrm{PhD}$, City University London. UK.

Kaufhold, K. 2008, "Young Adults Matter: A survey of television journalists on content, news presentation and young adults", Paper presented at the annual meeting of the Association for Education in Journalism and Mass Communication.

Levy, M. \& Windahl, S. 1984, "Audience activity and gratifications: A conceptual clarification and exploration.", Communication Research, vol. 11, pp. 51-78.

Marghalani, K., Palmgreen, P. \& Boyd, D. 1998, "The utilization of direct satellite broadcasting (DBS) in Saudi Arabia.", Journal of Broadcasting \& Electronic Media, vol. 42, no. 3, pp. 297314.

Miladi, N. 2006, "Satellite TV news and the Arab Diaspora in Britain: Comparing Al-Jazeera, the BBC and CNN", Journal of Ethnic and Migration Studies, vol. 32, no. 6, pp. 947-960.

Mokhtari, K. \& Sheorey, R. 1994, "Reading habits of university ESL students at different levels of English proficiency and education", Journal of research in Reading, vol. 17, no. 1, pp. 46-61.

Neuman, R.W., Just, M.R. \& Crigler, A.N. 1992, Common Knowledge: News and the Construction of Political Meaning, University of Chicago Press, Chicago.

O'Keefe, G. \& Spetnagel, H. 1973, "Patterns of college undergraduates' use of selected news media", Journalism Quarterly, vol. 50, pp. 543-548.

Pew Internet \& American Life Project 2010, Understanding the participatory news consumer: How internet and cell phone users have turned news into a social experience. Available: http://bit.ly/9RAeh7 [accessed on 25 March 2010].

Pew Research Centre for the People \& the Press 2002, , Public's News Habits Little Changed by September 11. Available: http://bit.ly/cqyy15 [accessed on 19 May 2010]. 
Robinson, J.P. \& Levy, M.R. 1986b, The Main Source: Learning from Television News, Sage Publications, Inc, Beverly Hills.

RT. 2010, , Russia Today TV channel. Available: http://rt.com/ [accessed on 28 September 2010].

Rugh, W. 2004, Arab Mass Media: Newspapers, Radio, and Television in Arab Politics, Praeger, London.

Sakr, N. 2007b, Arab Television Today, I.B. Tauris, London.

Schlagheck, C. 1998, "Newspapers Reading Choices by College Students.", Newspaper Research Journal, vol. 19, no. 2, pp. 14-74.

Sherr, S. 2005, "The next generation of news: can young people be engaged? Paper presented at the annual meeting of the International Communication Association", .

Thurlow, G.L. \& Milo, K.J. 1993, "Newspaper readership: Can the bleeding be stopped, or do we have the wrong patient?", Newspaper Research Journal, vol. 14, no. 3, pp. 34-44.

Vincent, R. \& Basil, M. 1997, "College students' news gratifications, media use and current events knowledge", Journal of Broadcasting \& Electronic Media, vol. 41, no. 3, pp. 380-392.

Walma van der Molen, J.H. \& van der Voort, T.H.A. 2000a, "Children's and adults' recall of television and print news in children's and adult news formats", Communication Research, vol. 27, no. 2, pp. 132-161.

Walma van der Molen, J.H. \& van der Voort, T.H.A. 1997, "Children's recall of television and print news: A media comparison study", Journal of Educational Psychology, vol. 89, no. 1, pp. 82-91.

Walma van der Molen, J.H. \& ven der Voort, T.H.A. 2000b, "The impact of television, print, and audio on children's recall of the news: A study of three alternative explanations for the dualcoding hypothesis", Human Communication Research, vol. 26, no. 1, pp. 3-26.

Wright, C. 1960, "Functional analysis and mass communication", Public Opinion Quarterly, vol. 24, no. 4, pp. 605-620.

Zayani, M. \& Ayish, M. 2006, "Arab Satellite Television and Crisis Reporting", International Communication Gazette, vol. 68, no. 5-6, pp. 473-497. 